\title{
A Note on the Existence of Periodic Solutions of Second Order Non-Linear Differential Equations
}

\author{
K. O. Olubowale ${ }^{1}$, D. T. Akomolafe, , $^{\text {, }}$ \\ ${ }^{1}$ Dept of Mathematics, Joseph Ayo Babalola University, Ikeji Arakeji, Osun State, Nigeria \\ ${ }^{2}$ Dept of Computer Science, Joseph Ayo Babalola University, Ikeji Arakeji, Osun State, Nigeria
}

\begin{abstract}
Bahman Mehri, using Leray - Schauder fixed point continuation method, established the existence of periodic solutions to equations of the form, $x^{\prime \prime}+(k+h(x)) x^{\prime}+f(t, x)=p(t)$, where $h$ is a continuous function, $f, p$ are continuous functions in their respective arguments and periodic with respect to $t$ of period $\omega$ and $\mathrm{k}$ is a constant.The aim of this research is to extend this result to a wider class of equations of the form, $x^{\prime \prime}+(k+h(x)) x^{\prime}+F\left(t, x, x^{\prime}\right)=p(t)$, where $F$ is continuous in $t, x$ and $\mathrm{x}^{\prime}$; and periodic with respect to $\mathrm{t}$ of period $\omega$ and $\mathrm{k}$ is a constant, using Leray-Schauder fixed point continuation method.
\end{abstract}

Keywords Nonlinear Equation, Sublinear Equation, Periodic Solutions, Fixed Points, Leray - Schauder, Continuation method, Boundedness of Solutions and Continuous Functions

\section{Introduction}

Recently, Bahman Mehri in(2) established the existence of periodic solutions to equations of the form

$$
\mathrm{x} / /+(\mathrm{k}+\mathrm{h}(\mathrm{x})) \mathrm{x}^{\prime}+\mathrm{f}(\mathrm{t}, \mathrm{x})=\mathrm{p}(\mathrm{t})
$$

Where $h$ is a continuous function $f, p$ are continuous and periodic with respect to $t$ of period $\omega$.

The method of proof adopted in the paper consist mainly of leray - schauder fixed point continuation argument as enunciated in[4]

$\operatorname{In}[2]$, the case when $f(t, x)$ is sublinear in $x$ was considered which is evident in the assumption(iii) of Bahman Mehri main theory namely that

$$
\left.|\mathrm{x}|^{-1}|\mathrm{f}(\mathrm{t}, \mathrm{x})|\right) \rightarrow \mathrm{o} \text { as }|\mathrm{x}| \rightarrow \infty
$$

uniformly in t.

In this paper, we shall extend Bahman Mehri's result to a wider class of equations of the form.

$$
\mathrm{x}^{\prime \prime}+(\mathrm{k}+\mathrm{h}(\mathrm{x})) \mathrm{x}^{\prime}+\mathrm{F}\left(\mathrm{t} \_\mathrm{x} ، \mathrm{x}^{\prime}\right)=\mathrm{p}(\mathrm{t})
$$

Where $F$ is continuous and periodic with respect to $t$ of period $\omega$.

In this paper, we shall impose the following condition on $\mathrm{F}$ namely that

$$
\left.\left.|x|^{-1(}\left|F\left(t, x, x^{\prime}\right)\right|\right)\right) \rightarrow 0
$$

as $|\mathrm{x}| \rightarrow \infty$, uniformly in $\mathrm{t}$.

In section 2, we state Bahman Mehri's result, together with the statement of our main theorem and its proof.

* Corresponding author:

dtakomolafe@yahoo.com (D. T. Akomolafe)

Published online at http://journal.sapub.org/ajms

Copyright (C) 2012 Scientific \& Academic Publishing. All Rights Reserved

\section{Problem Analysis}

Second order ordinary differential equations(1.2) arise in nature especially in problems that has to do with oscillatory

motions of an object and the motion of a simple pendulum .For a pendulum observing a simple Harmonic motion the motion is described by second order ordinary differential equations of the form

$$
\mathrm{x}^{\prime /}+\mathrm{h}(\mathrm{x}) \mathrm{x}^{\prime}+\mathrm{b} \sin \mathrm{x}=0
$$

where $\mathrm{b}$ is a constant and $\mathrm{h}(\mathrm{x}) \mathrm{x}^{\prime}$ is the damping term . Equation(1.2) is a generalized form of equation(2.1). We shall consider the periodic oscillations of equation(1.2) in this paper.

The effect of the damping is to slow down the motion of the object .The experiment is designed in such a way as to neutralize the effect of whatever damping that might affect the outcome of the experiment by imposing necessary conditions on the motion of the object. It is to be noted that solutions to equation(1.2) has a wider application than the solutions to equation $(1,1)$

\section{Objective}

Differential equation of the form(1.2) occurs in many oscillations problems in both mechanical and electrical system occurring in nature. The objective of carrying out this research work is to study oscillatory phenomena like the existence of periodic solutions to a class of second order ordinary differential equations using Leray_Schauder fixed point continuation method 


\section{Methods}

In this section, we shall state Bahman Mehri's result for equation(1.1) and also state our main theorem for equation(1. 2 ) together with the statement of its proof.

\section{Theorem 4.1}

$\operatorname{In}[2]$ Bahman Mehri established the proof of the following theorem

Equation( 1.1) admits at least one $\omega$ - periodic solution if

(i) $\int_{0}^{\mathrm{w}} p_{(t)} d_{t}=0$

i.e $\quad \alpha(\mathrm{t})=\int_{0}^{\mathrm{w}} p(t) d_{t}=0 \quad$ is $\omega$-periodic

(ii) $|\mathrm{H}(\mathrm{z})| \leq \mathrm{M}_{1}\left[\mathrm{H}(\mathrm{z})=\int_{0}^{w} h(s) d_{s}=0\right]$

(iii) $|\mathrm{x}|-1(|\mathrm{f}(\mathrm{t}, \mathrm{x})|) \rightarrow \mathrm{o}$ as $|\mathrm{x}| \rightarrow \infty$, uniformly in $\mathrm{t}$

(iv) $\mathrm{f}(\mathrm{t}, \mathrm{x}) \operatorname{sgn} \mathrm{x} \geq \mathrm{o}, \quad|\mathrm{x}| \geq \mathrm{b}$

\section{Theorem 4.2}

Equation(1.2) admits at least one $\omega$ - periodic solution if

$$
\text { (i) } \int_{0}^{\mathrm{w}} p_{(t)} d_{t}=0
$$

i.e $\quad \alpha(\mathrm{s})=\int_{0}^{\mathrm{w}} p(s) d s=0$ is $\omega$-periodic

(ii) $|\mathrm{H}(\mathrm{z})| \leq \mathrm{M}_{1}\left[\mathrm{H}(\mathrm{z})=\int_{0}^{w} h(s) d_{s}=0\right]$

(iii) $\left.|\mathrm{x}|^{-1(}\left|\mathrm{F}\left(\mathrm{t}, \mathrm{x}, \mathrm{x}^{\prime}\right)\right|\right)=0$

as $|\mathrm{x}| \rightarrow \infty$, uniformly in $\mathrm{t}$.

(iv) $\mathrm{F}\left(\mathrm{t}, \mathrm{x}, \mathrm{x}^{\prime}\right) \operatorname{sgn} \mathrm{x} \geq \mathrm{o}$ for all $\mathrm{t}, \mathrm{x}$, and $\mathrm{x}^{\prime}$ for $|\mathrm{x}|+\left|\mathrm{x}^{\prime}\right| \geq \mathrm{b}$

\section{Proof of Theorem 4.2}

The proof is based on the Leray - Schauder fixed point continuation method. The corresponding continuation equation of equation (1.2) is

$\mathrm{x}^{\prime \prime}+\mathrm{kx} \mathrm{x}^{\prime}+\mathrm{cx}=\mu\left[\mathrm{p}(\mathrm{t})-\mathrm{F}\left(\mathrm{t}, \mathrm{x}, \mathrm{x}^{\prime}\right)+\mathrm{cx} \mathrm{x}^{\prime \prime}-\mathrm{xh}(\mathrm{x})\right](4.7)$

Where $\mathrm{c}$ is an arbitrary positive constant and $0 \leq \mu \leq 1$

For $\mu=\mathrm{o}$, we obtain a homogenous linear equation

$\mathrm{x}^{\prime \prime}+\mathrm{kx}^{\prime}+\mathrm{cx}=0$

where $\mathrm{k}$ and $\mathrm{c}$ are constants, $\mathrm{c}$ is positive

Which has the trivial solution $\mathrm{x}(\mathrm{t})=0$ as its only $\omega$ - periodic solution.

For $\mu=1$, equation( 4.7) is the original equation(1 .2).

Following the presentation in[2] and[4], equation(4.7) admits at least one periodic solution for each parameter value $\mu \varepsilon[0,1)$ if for $0<\mu<1$ all periodic solutions of equation( 4 . 7) are bounded. We write.

Let $x(t)=x(t+\omega)$ be a solution of equation(4.7) and let $0<\mu<1$, we write:

$R={ }_{\text {max }}|x(t)|$ for $0 \leq t \leq \omega$

$\left|\mathrm{F}\left(\mathrm{t}, \mathrm{x}, \mathrm{x}^{\prime}\right)\right|=\operatorname{Ro}(|\mathrm{x}|),($ small o) for $|\mathrm{x}(\mathrm{t})| \leq \mathrm{R}$ and $0 \leq \mathrm{t} \leq \omega$

Let $\mathrm{y}=\mathrm{x}^{\prime}$, then $\mathrm{y}$ satisfies the boundary value problem

$$
\begin{aligned}
y^{\prime}+k y & =q(t) \\
y(0) & =y(\omega)
\end{aligned}
$$

Where

$\mathrm{q}(\mathrm{t})=\mu\left\{\mathrm{p}(\mathrm{t})-\mathrm{F}\left(\mathrm{t}, \mathrm{x}(\mathrm{t}), \mathrm{x}^{\prime}(\mathrm{t})\right)-\mathrm{h}(\mathrm{x}(\mathrm{t})) \mathrm{x}^{\prime}(\mathrm{t})\right\}-(1-\mu) \mathrm{cx}^{\prime}(\mathrm{t})$ is periodic in $t$ and $q(t+\omega)=q(t)$.
Introducing the Green function

$$
G(t, s)= \begin{cases}\frac{e^{k(s-t-\omega)}}{e^{-k \omega}-1}, 0 \leq s t \leq s \leq \omega \\ \frac{e^{k(s-t)}}{e^{-k \omega}-1}, 0 \leq s t \leq s \leq \omega\end{cases}
$$

Where $G(t+0, t)-G(t-0, t)=1$, of the boundary value problem(4 .9), We obtain the following representation of the solution $\mathrm{y}(\mathrm{t})$.

$$
\mathrm{y}(\mathrm{t})=\int_{0}^{w} G(t, s) q(s) d \mathrm{~s}=0
$$

Replacing $\mathrm{q}(\mathrm{t})$ by the term $\mathrm{h}(\mathrm{x}(\mathrm{t})) \mathrm{x}(\mathrm{t})$ which occurs in the expression for $\mathrm{q}(\mathrm{t})$ we obtain

$$
\begin{gathered}
\mathrm{y}(\mathrm{t})=[\mathrm{h}(\mathrm{x}(\mathrm{t})) \mathrm{G}(\mathrm{t}, \mathrm{s})]_{\mathrm{o}}^{\mathrm{t}-0}-\int_{0}^{w} G t(t, s) H(x(s)) d s \\
+(\mathrm{H}(\mathrm{x}(\mathrm{t})) \mathrm{G}(\mathrm{t}, \mathrm{s}))^{\omega}{ }_{\mathrm{t}+0} \\
\mathrm{Gt}(\mathrm{t}, \mathrm{s})_{=} \frac{\partial \mathrm{G}(\mathrm{t}, \mathrm{s})}{\partial \mathrm{t}}
\end{gathered}
$$

Hence

$$
y(t)=h(x(t))_{0}{ }^{\omega}-G_{t}(t, s) H(x(s) d s
$$

Inserting the explicit expression for $\mathrm{q}(\mathrm{t})$ in equation( 4.12$)$ we have after some simplification,

$$
|y(t)|=\left|x^{\prime}(t)\right| \leq \omega \rho\left[m+2 M+c R+\operatorname{Ro}\left(\left|x^{\prime}\right|\right)\right]
$$

Where $\rho=\max \left\{1,{ }^{1} / \mathrm{k}\right\}$

$\mathrm{m}=\max |\mathrm{p}(\mathrm{t})|$ for $0 \leq \mathrm{t} \leq \omega$

$\mathrm{M}=\max |\mathrm{H}(\mathrm{x}(\mathrm{t}))|$ for $0 \leq \mathrm{t} \leq \omega$

Therefore

$|\mathrm{x}(\mathrm{t})| \leq \omega \rho(\mathrm{m}+2 \mathrm{M}+\mathrm{cR})+\mathrm{o}(\mathrm{R}) \tau$

Now term by term integration of equation(4.7)( for periodic solution) yields

$$
\begin{aligned}
& {\left[x^{\prime \prime}(t)+k x^{\prime}(t)+H(x(t))-\mu\left[x^{\prime \prime}(t)+k x^{\prime}(t)+H(x(t))-\mu \int_{0}^{t} p(s) d s\right]_{0}^{w}\right.} \\
& +\int_{0}^{\omega}\{(1-\mu) c x,(t)+\mu F(t, x(t))\} d t=0
\end{aligned}
$$

Since $1-\mu>0$, and we have

$$
\left\{(1-\mu) \mathrm{cx}^{\prime}(\mathrm{t})+\mu \mathrm{F}\left(\mathrm{t}, \mathrm{x}(\mathrm{t}), \mathrm{x}^{\prime}(\mathrm{t})\right)\right\} \operatorname{sgn} \mathrm{x}>0
$$

For $\left(|x(t)|+\left|x^{\prime}(t)\right|\right)>b$ and for $t \varepsilon[0, \omega]$

Combining(4.17), (4.18) and (4.19) we get a contradiction.

It follows that case

$\left(|x(t)|+\left|x^{\prime}(t)\right|\right)>b$ is excluded.

Therefore, there exists for $0<\mathrm{t}<\omega$ such that

$\left(|\mathrm{x}(\mathrm{t})|+\left|\mathrm{x}^{\prime}(\mathrm{t})\right|\right) \leq \mathrm{b}$.

Applying the means - value theory to an arbitrary inter$\operatorname{val}(\mathrm{t}, \mathrm{t}) \leq[\mathrm{t}, \mathrm{t}]<[\mathrm{t}, \mathrm{t}+\omega]$, we have,

Hence

$$
|x(t)-x(\tau)|=|t-\tau| \mid y(t+\theta)(t-\tau \theta)) \mid
$$

Therefore

$$
\left|\mathrm{x}^{\prime}(\mathrm{t})\right|<\mathrm{b}+\omega^{2} \rho(\mathrm{m}+2 \mathrm{M}+\mathrm{cR})+\mathrm{o}(\mathrm{R})
$$

If $|X(t)| \leq$ Ro for $0 \leq t \leq \omega$

then

and

$$
|x(t)| \leq b+\omega^{2} \rho\left(m+2 M+c R_{o}\right)
$$

$$
|\mathrm{x}(\mathrm{t})| \leq \omega \rho\left(\mathrm{m}+2 \mathrm{M}+\mathrm{cR} \mathrm{o}_{\mathrm{o}}\right)+\mathrm{o}\left(\mathrm{R}_{\mathrm{o}}\right) \text { as } \mathrm{R}_{\mathrm{o}} \rightarrow \infty
$$


This completes the proof of the theorem.

\section{Remarks}

i.v In the case

$$
\begin{aligned}
& \mathrm{F}\left(\mathrm{t}, \mathrm{x}, \mathrm{x}^{\prime}\right) \operatorname{sgn} \mathrm{x} \leq 0 \text { and } \\
& |\mathrm{x}|+\left|\mathrm{x}^{\prime}\right| \geq \mathrm{b}
\end{aligned}
$$

we introduce a new independent variable $t=-\tau$ and obtain a differential equation of previous type.

\section{Results}

\section{Example 1}

In the equation

$\mathrm{x}^{\prime \prime}+(1+\operatorname{Sin} \mathrm{x}) \mathrm{x}^{\prime}+\mathrm{x}^{1 / 3}\left(\operatorname{Sin}^{2} \mathrm{t}+\operatorname{Cos}^{2} \mathrm{x}^{\prime}=\operatorname{Sin} \mathrm{t}\right.$

All the conditions of theorem 4.2 are satisfied.

Hence, the equation possess at least one $2 \pi$ - periodic solution

\section{Example 2}

Also in the equation

$\mathrm{x}^{\prime \prime}+.(1+\exp (-\mathrm{x})) \mathrm{x}^{\prime}+\mathrm{x}($ to power $2 / 3)=\mathrm{cos} \mathrm{t}$

All the conditions of theorem 4.2 are satisfied

\section{Discussion}

From the theory of differential equations, Theorem 4.2 assured us the existence of periodic solutions to equation 1.2 when the functions $\mathrm{p}(\mathrm{t}), \mathrm{h}(\mathrm{x}), \mathrm{F}(\mathrm{t}, \mathrm{x}, \mathrm{x})$ satisfy suitable conditions in ther respective arguments. Theorem 4.2 is applicable to the wider class of equations 1.2 while theorem4.1 of Bhaman Mheri[2] is only applicable to the class of equations1.1. Thus our theorem 4.2 is an improvement over therem4.1 of Bhaman Mheri.

\section{Conclusions}

Having been assured of the existence of periodic solutions to equations 1.2 , we may proceed to get the approximate solutions if analytical solutions are not obtainable. In addition, if the system of equations 1.1 and 1.2 satisfy initial conditions $\mathrm{x}\left(\mathrm{t}_{\mathrm{o}}\right)=\mathrm{y}_{\mathrm{o}}, \quad \mathrm{x}^{1}\left(\mathrm{t}_{\mathrm{o}}\right)=\mathrm{y} 1$, we can then obtain a unique periodic solutions

\section{REFERENCES}

[1] Cesari, L.,(1963) "Functional Analysis and Periodic Solution of Nonlinear Differential Equations" Contributions to Differential Equations I , pp 149 - 187

[2] Mehri, B.,(1989) "Periodic Solutions of a second order Non linear Different Equation” Bull Austral . Math. Soc ., col. 40, pp $357-361$

[3] Olubowale, K.O.,(1989) "Oscillation of a Class of Perturbed Second Order Non - Linear Ordinary Differential Equations'. Unpublished M.Sc. Thesis, Obafemi Awolowo University, Ile - Ife

[4] Reissig, R.S., Sansone, G and Conti. R., "Non(1974) linear Differential Equations of higher order" Noordhoff International Publishing Leyden. 